\title{
Introduction to the special section on Activity Theory for Work Analysis and Design
}

\author{
Pascal Béguina ${ }^{\mathrm{a}}$ Francisco Duarte ${ }^{\mathrm{b} *}$, Laerte ldal Sznelwar \\ anniversité Lumière Lyon 2, Lyon, France. \\ b*Universidade Federal do Rio de Janeiro, Rio de Janeiro, RJ, Brasil, fjcmduarte@gmail.com \\ 'Universidade de São Paulo, São Paulo, SP, Brasil.
}

The collection of eleven ergonomics papers ${ }^{(1)}$ published in this section of the International Journal of Production Ergonomics includes the best papers selected from the symposium, Activity and Innovation, organized by the Technical Committee for Activity Theory for Work Analysis and Design (ATWAD) that was held during the Triennial World Congress of the International Ergonomics Association at Recife in 2012.

The International Ergonomics Association (IEA) is a federation of ergonomics organizations from around the world. 1ts main goal is to advance the science and practice of ergonomics on an international level. To achieve this goal, the IEA relies on technical committees, which are platforms to exchange information on a particular field. The specific objectives of the Technical Committee for ATWAD, founded in 2005 by Pascal Béguin and supported by SELF (the French Speaking Ergonomics Association), are to document and to disseminate theories and methods based on activity approaches and to contribute on that basis to work system design.

Etymologically, ergonomics comes from the old Greek words érgon (work or job) and nómos (law or rules). However, as argued by many ergonomists, two fundamental issues are to be considered to understand work: the what and the how, meaning what workers have to do and how they do it. At a basic level, work activity is a conceptualization of how workers complete the job. However, the basic question of human activity raises theoretical and practical problems of an extreme complexity. Work activity questions conceptualizations that stem from physiology (gestural sequences, tiredness and physical health), psychology (information process, representation or sense-making), sociology (collective work and power in work settings), or anthropology (the impact of culture on work practices), etc. Currently, the concept of human activity is actively discussed within a large community of international researchers, which come from different traditions and backgrounds (cultural and historical activity theory, situated approaches of action and cognition, workplace studies, etc.). The challenge pursued by this community is to consider that the knowledge produced regarding work activity is useful for designing work systems, jobs and products to make them compatible with the needs, abilities and limitations of people. The papers collected in this section particularly focus on innovation.

Innovation is an ongoing problem in many social sciences such as economics, management and sociology. In their entirety, the papers published in this section focus on innovation, the understanding of work as the meeting of a novelty (either technical and/or organizational) with a working community (in its cognitive, social, historical or cultural dimensions). The aim is to document innovation from the human work activity point of view and to discuss ergonomic contributions and methods for innovation and change. The collection

\footnotetext{
(1) One of them (Contradiction analysis: towards a dialectical approach in ergonomics field interventions written by Nathanael, D.; Zarboutis, N. and Marmaras, N.) was published in the previous Production Journal number - v.25, n1, p 223-231.
} 
can be divided in three sections. The first section includes four articles, aimed at describing and defining innovation from an activity standpoint. Based on a French Brazilian project, Duarte et al. discuss work activity within sustainable development, and Querol et al. focus on the motivational perspective of workers who produce biogas. Seppanen et al. analyze fluency logic after innovation in railway traffic in Finland, and Kerosuo et al. discuss the change introduced by building information modeling and the effect on construction projects. In the second section, four other papers are centered on methods for innovation. Oggioni et al. discuss ergonomic guidelines from an activity viewpoint during design. Castro et al. analyze user contribution to an architectural design project at the beginning of its use, and Brunoro et al. discuss the contribution of bus drivers to the efficiency of public transportation in Sao Paulo. In the final paper, Mondeto discusses the difficult task for farmers to develop new competences. The collection is closed by two papers, which are centered on the relationship between innovation and health. Speaking of innovation often leads to discussions on the subject of its desired effects. However, the unexpected effects, particularly on health and work, are often missing. Van de Veert and Barrata discuss the impact of change on healthcare workers, whereas Hubault and Sznelwar focus on the important question of subjectivity.

The Triennial IEA Congress was held in Recife, the TC ATWAD showed interest in design and engineering production, and the focus of the conference was primarily on ergonomics and work safety (one of topics of the editorial policy of that journal). These facts provided a unique opportunity to publish the works collected here in the International Journal of Production Ergonomics. We wish you a successful and fruitful reading! 